\title{
Promoting Public Good and Wellness From the Perspective of a Midwestern Regional Baptist Church Community-led Research Engagement Partnership
}

\author{
Rebecca Johnson, ${ }^{1}$ Diana Ingram ${ }^{2}$, Bishop Simon Gordon ${ }^{3}$, and Paris Davis ${ }^{4}$ \\ ${ }^{1}$ Independent Researcher, formerly Center for Community Health and Department of Medical Social Sciences, \\ Feinberg School of Medicine, Northwestern University, ${ }^{2}$ Department of Healthcare, American College of Education \\ formerly Rush University Medical Center , ${ }^{3}$ Triedstone Full Gospel Baptist Church, and ${ }^{4}$ Total Resource Development \\ Organisation Triedstone Full Gospel Baptist Church
}

Cite as: Johnson, R., Ingram, D., Gordon, S., and Davis, P. (2020). Promoting Public Good and Wellness From the Perspective of a Midwestern Regional Baptist Church Community-led Research Engagement Partnership. Metropolitan Universities, 31(3), 44-69. DOI: 10.18060/24054

This is an open access article distributed under the terms of the Creative Commons Attribution License.

Editor: Valerie L. Holton, Ph.D.

\section{Abstract}

Faith-based communities supporting diverse and underserved communities are increasingly being recognized by researchers as community "anchor institutions" and equitable partners in research engagement. Research suggests that faith-based organizations (FBOs) can promote health and well-being within congregations and throughout communities. This evidence has energized community-academic partnerships to collaboratively support FBOs in plans to improve community wellbeing and health equity, particularly within communities of color. This paper describes the evolution of a community-academic collaboration led by a Full Gospel Midwest Regional Baptist Church where the co-partners professed a commitment to advancing the public good through collaborative governance and shared goal setting in the delivery of an engagement training program. Core features highlighted are: (1) establishing a Community Advisory Board; (2) developing a research engagement training program; and (3) analyses, results, and legacy. Extension of the church-led mission to lead research engagement connects leaders and communities to resources and scientific expertise in support of the data needs and aspirations of faith-based communities. As research-ready partners, faith-based communities have the capacity to function as localized anchors to drive urban health policy and to serve as advocates by being the "voice" in community-driven research engagement for "public good." 
Keywords: faith-based communities, shared decision-making, engagement, public good and wellness, full gospel, research ministry ambassadors, Pastors4PCOR

\section{Introduction}

"Expand to the right and to the left, and your descendants will inherit the nations, and make the desolate cities inhabited" (Isaiah 54:2-3)

Nationwide urban institutions of higher education educate about 20 million students annually and are significant economic anchors or place-based institutions within cities and the nation. In Chicago, public and private higher education institutes identify and have been identified as anchor institutions that actively embrace the "public good." (CASE, 2020; Perry, 2018; Murasse, 2001). Universities have led partnership projects to further place-based social causes and human flourishing (Bamk et al., 2018) and improve the economic health of local neighborhoods (CASE, 2020). Institutions with hospital systems are also working together to improve patient experience via patient engagement. Chicago, for example, is home to both the Chicago Consortium for Community Engagement, established in 2008, and the Area Patient-Centered Outcomes Research Network, established in 2013. The Chicago Consortium for Community Engagement (C3) takes advantage of the significant federal investment of the National Institutes of Health in Chicago's Clinical and Translational Science Institutes to ensure that local research is conducted collaboratively with communities in efforts to make research findings more relevant and available to the public more effectively and efficiently. C3's mission is to maximize the impact of community-engaged research, improve population health and health equity throughout greater Chicago and actively engage researchers, community stakeholders, policy makers, and others who share a common vision for a healthier Chicago (C3 partners are listed in Appendix A).

Pastors4PCOR (P4P) is a faith-based research engagement initiative that serves as a community liaison ready to partner with research institutions and public health networks. More specifically, and directly impacting P4P's current focus on building a Community Support HUB for connecting patients, stakeholders and researchers (PCORI, 2019), is C3's work with the Chicago Department of Public Health (CDPH). The wider availability of big data which impacts health on a daily basis has sparked renewed focus on the health disparities and inequities which exist in the city from multiple perspectives. Understanding the particular mix of underlying health conditions and health factors in different communities has become a city hall priority (CDPH, 2020). C3's 2017 appointment of a CDPH coordinator laid the groundwork for a reciprocal working relationship between $\mathrm{P} 4 \mathrm{P}$ and $\mathrm{CDPH}$. The coordinator is a respected and valued HUB Community Advisory Board (CAB) member, linking CAB and HUB Community of Resource Enrichment (CORE) members to $\mathrm{C} 3, \mathrm{CDPH}$, and other community place-based anchors and Support, Partner, Opportunities, Knowledge, Expertise, and Services (SPOKES) (See Figure 1).

(C) The Author 2020. Published by the Coalition of Urban and Metropolitan Universities. www.cumuonline.org Metropolitan Universities | DOI 10.18060/24054 | December 18, 2020 
Unlike C3, the Chicago Area Patient-Centered Outcomes Research Network (CAPriCORN)'s mission is to advance patient-centered research across Chicago. Specially, to develop, test, and implement policies and programs designed to improve health care quality, health outcomes, and health equity for the diverse populations of Chicagoland and beyond. Since 2014, CAPriCORN has worked to put in place the infrastructure and processes necessary to create data sets comprised of high-quality, de-duplicated patient information. Eleven (11) different health systems (see Appendix A) contribute strategic leadership, data, and/or data stewardship. CAPriCORN is one of nine Clinical Research Networks (CRNs) supported by the National Patient Centered Clinical Research Network (PCORnet) that originated from the PatientCentered Research Institute, (2013). More specifically, and directly impacting P4P's capacity to build and sustain a Community Support HUB for connecting patients, stakeholders and researchers, is the legacy of engaged partnership between P4P and CAPriCORN leaders and members since 2013. For example, a founding member of the original $\mathrm{P} 4 \mathrm{P} \mathrm{CAB}$ was also a founding member of CAPriCORN's Patient Community Advisory Committee (2013).

$\mathrm{C} 3$ and CAPriCORN illustrate the powerful added value of networks hosted by urban universities and the expertise hosted within affiliated research hospitals, other health systems, and city departments. Partnership between networks like these and community place-based anchors, such as $\mathrm{P} 4 \mathrm{P}$, have considerable potential. The literature for researcher-initiated community engagement, for example, showcases mutually beneficial partnerships between the urban university, civic foundations, and other community place-based anchors. Indeed, these partnerships can deliver sustainable place-based communities and reduce neighborhood health inequities (Harkavy, 2018; Fritz et al., 2019). However, despite the proliferation of "public good" partnerships, measuring the size and significance of that identification and the impact on communities has remained elusive. Universities tend to measure what they are required to measure (Friedman et al., 2014) and community partners are rarely afforded the experience of informing research questions asked, collecting and analyzing data, or the opportunity to disaggregate data for their own use (Friedman et al., 2014). Additionally, as noted by the Coalition of Urban Serving Universities, "resources, not mission often drive data collection efforts" (Friedman et al., 2014) with partnership priorities and investments changing over time in response to funding as much as societal need. Further as several authors have observed "the persistent health inequities impacting communities close to wealthy urban universities raise troubling moral issues, as well as, questions about higher education's contribution to the public good" which become particularly apparent during times of emergency (Harkavy, 2016; Scriven, 2011).

In this article, we focus on the evolution of Pastors4PCOR (P4P), a faith-based research engagement initiative. Triedstone Full Gospel Baptist Church (FGBC) is located on Chicago's southside. Triedstone's church leader is Bishop Simon Gordon. Under Bishop Gordon's direction, the Midwest Region of FGBC provides localized accessible health-related information, services and resources that are much needed by local community residents. These initiatives are

(c) The Author 2020. Published by the Coalition of Urban and Metropolitan Universities. www.cumuonline.org Metropolitan Universities | DOI 10.18060/24054 | December 18, 2020 
managed through the Triedstone church's community outreach hub, Total Resource Community Development Organization (TRCDO). TRCDO was established as a 501(c)3 entity in 2000 to assist at-risk families in need of immediate wraparound support services. TRCDO's mission is to help close service gaps by functioning as a one-stop resource that offers onsite programs and linkages for providing daily living resources and support. For over 20 years, TRCDO has successfully accomplished this goal through collaborative relationships within the faith-based community, varying local entities and governmental agencies, including the formation of Pastors4PCOR (P4P) in 2013. TRCDO annually reaches over 25,000 individuals directly through health awareness and prevention programs, food pantry, HUD housing counseling, CEDA assistance, and training and development programs.

Since its inception in 2013, P4P has partnered with multiple stakeholders across Chicagoland to pave the way for a community support HUB capable of connecting patients, stakeholders and researchers (PCOR, 2019). Valued stakeholders have included Southland Health Minsters Network; medical and academic researchers from Northwestern University (NU); Rush University Medical Center (RUMC); Illinois Institute of Technology (IIT); University of Illinois at Chicago (UIC), University of Chicago (UC), Loyola University; Cook County Health Systems (CCHS); faith-based community-based patients and caregivers; and church leaders and members. Initially, P4P focused on building a community advisory board (CAB), and members were recruited from those valued stakeholders listed above. The CAB managed the development of a research engagement training program for church leaders and members designated as trainee Research Ministry Ambassadors (RMA). Now, as illustrated in Figure 1, P4P is building out a Community Support HUB to sustain support and navigation for collaborative partners interested in community engagement

Figure 1. Building a Community Support HUB (PCORI, 2019) and sample research engagement.

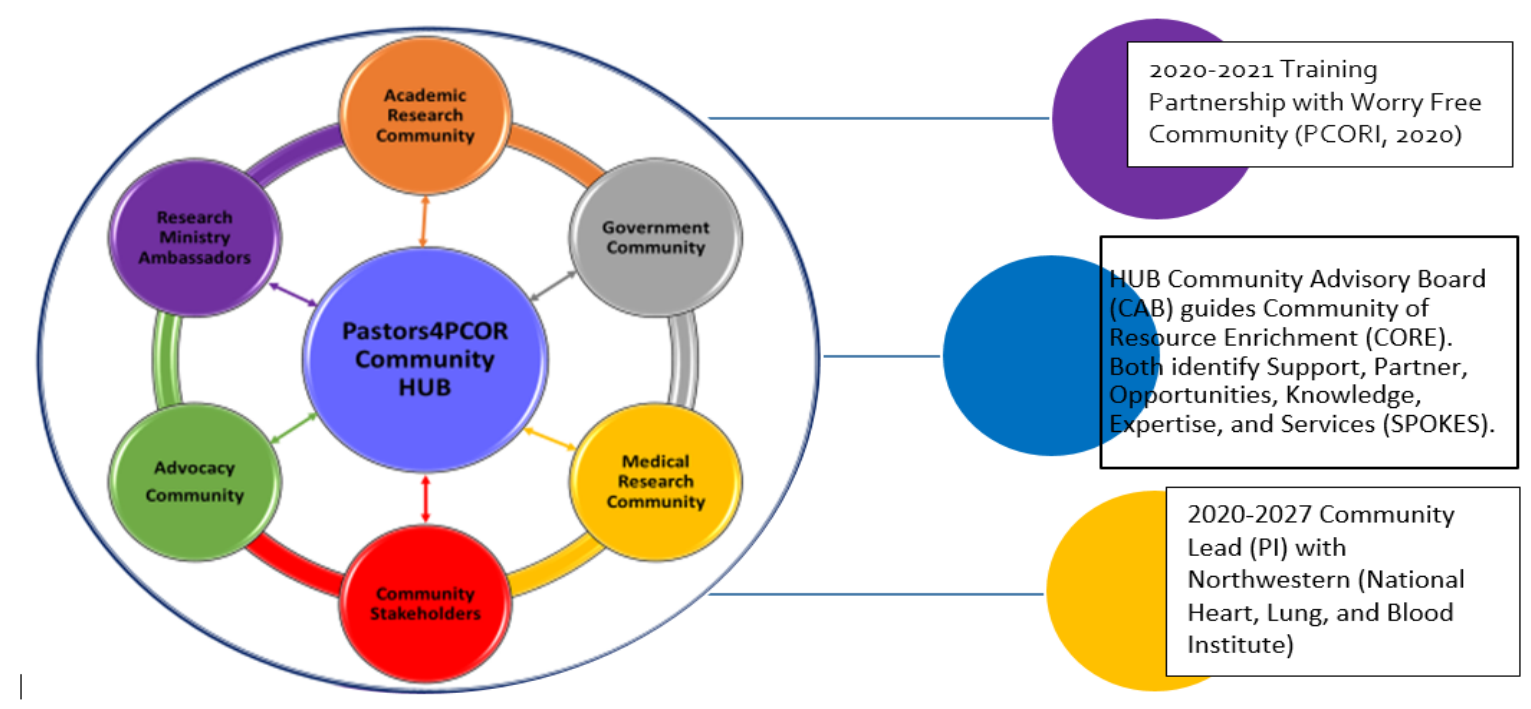

(C) The Author 2020. Published by the Coalition of Urban and Metropolitan Universities. www.cumuonline.org Metropolitan Universities | DOI 10.18060/24054 | December 18, 2020 


\section{Context}

Community-initiated research engagement with research institutions is well documented (JewettTennant, et al., 2016; Adebayo, et al., 2018; Campbell, et al., 2007). Systematized review of the growing body of literature suggests faith-based communities are heavily invested in the processes of reciprocal relationship building, regularly connecting congregations to healthcare knowledge and information (DeHaven, et al., 2004; Kang, 2016; Khubchandani, et al., 2016, Olivier, 2017; Brooks, et al., 2002; Tucker, et al., 2017; Sanders, 2016). Published research on community engaged research with faith-based community anchors shows recurrent positive impact via a range of initiatives, particularly those with a preventive or behavioral and educational focus. Cardiovascular health, diabetes, cancer, depression, dementia, nutrition, and physical activity (Brewer et al., 2017; Hankerson et al., 2013; Hou, 2017; Misra, 2016; Plunkett, 2015; Campbell et al., 2007) are all topic areas where researchers and faith-based communities have effectively engaged. Factors which have impeded researcher-initiated engagement include researcher misunderstanding about faith-based community infrastructure, historic mistrust of research institutions, and faith-based community misunderstanding of communication by healthcare providers (Kiger, 2017).

P4P's community engaged work should be understood with reference to the patient engagement rubric and framework for practice defined by PCORI (PCORI, 2014). To clarify, whilst community engaged and community based participatory research is characteristically defined by its mission to increase knowledge and understanding of a given phenomenon and to integrate the knowledge gained with interventions for policy or social change benefiting the community members (Stoecker et al., 2003), the mission for PCORI engagement awardees is to build capacity of patients, caregivers, stakeholders, and consumers of the broader healthcare community to engage in patient-centered outcomes research. PCORI's mission is to help people make informed healthcare decisions, and improve healthcare delivery and outcomes, by producing and promoting high-integrity, evidence-based information that comes from research guided by patients, caregivers, and the broader healthcare community. In PCORI-funded research, patients and other healthcare stakeholders are equitable partners, as opposed to research subjects, who leverage their lived experience and expertise to influence research to be more patient centered, relevant, and useful. Their early and continued involvement throughout a study can lead to greater use and uptake of research results by patients and stakeholders within the healthcare community.

Many faith-based communities support and serve vulnerable and minority populations who experience the poorest health outcomes and adverse impact of health disparities shown by local and national health statistics. Faith-based organizations are "beloved communities" (Warren et al., 2011), a term which Martin Luther King Jr. used to signify a society based on justice, equal opportunity, and love of one's fellow human beings. ...also one in which all are embraced and none discriminated against. Community members are supported by a "healthy grapevine"

(C) The Author 2020. Published by the Coalition of Urban and Metropolitan Universities. www.cumuonline.org Metropolitan Universities | DOI 10.18060/24054 | December 18, 2020 
capable of disseminating and sharing health information during events like prevention screenings, community health fairs, and after-school programs. For example, recently faith-based communities have become essential to the front-line response to virulent coronavirus (COVID19) pandemic by offering drive through food banks, as well as, ongoing ministry support. The effects of COVID-19 on the health of racial and ethnic minority groups is still emerging (CDC, 2020; Chicago Urban League, 2020), however, the data suggests a disproportionate burden of illness and death among racial and ethnic minority groups. Due to ongoing health disparities and inequities, those of us who live and/or work within communities of color are not surprised that this current global health crisis of a COVID-19 pandemic places communities of color and minorities at higher risk of poor adverse outcomes and/or death from virus related complications. Early scientific COVID-19 data and reports indicate that people with existing chronic health problems and/or co-morbid health conditions such as cardiovascular diseases, diabetes, cancers, and asthma are more vulnerable to the disease (Chicago Urban League 2020) and "the majority of the black COVID-19 patients who died had underlying health conditions including respiratory problems and diabetes. $81 \%$ had hypertension or high blood pressure, diabetes or both." More recent report of new CDC data, for example, The Marshall Report, 2020, shows deaths in Illinois from all causes, COVID and otherwise, have gone up 9\% among White Americans, but more than $30 \%$ in communities of color $(+37 \%$ Black; $+70 \%$ Latinx; $+54 \%$ Asian $)$. Online city and local media updates on COVID-19 cases and deaths has placed a magnifying glass on preexisting inequities in our communities with residents able to search Chicago by zip code for updates on mortality rates within racial and ethnic community areas (CDPH, 2020; South-Side Weekly, 2020).

Triedstone's Bishop Simon Gordon has a history of leadership within the Full Gospel Baptist Church Movement with regional and international ties, as well as, networking with national and local policy makers and politicians. Most recently, Bishop Gordon and other clergy heeded the Governor of Illinois' service call to join and work closely with his COVID-19 Health Equity Taskforce (Chicagobusiness, 2020). Within communities of color, minorities, and low-income earning families, the impact of the COVID-19 pandemic is devastating for communities already experiencing living conditions where there are food deserts, limited access to healthcare, and sparse affordable housing. During this pandemic, faith-based leaders and the (Illinois) Health Equity Taskforce face the "ethical challenge of doing good in the face of chaos" by arranging for a fair distribution of health resources and more accessible COVID-19 testing sites in the predominately at-risk African American communities in order to "put our community on a better place for longevity and strength" (Earl, 2011; Scriven, 2011). Church leaders have also taken the lead in messaging the governor's mandate of social distancing and size limits to gatherings, including offering virtual spiritual services.

Triedstone's response to the COVID-19 pandemic is a recent illustration of how quickly and effectively faith-based communities can mobilize and respond to public health crises. The unique combination of collaborative partnership and networking on display within and beyond the State

(C) The Author 2020. Published by the Coalition of Urban and Metropolitan Universities. www.cumuonline.org Metropolitan Universities | DOI 10.18060/24054 | December 18, 2020 
of Illinois illustrates how faith-based organizations are uniquely placed to network with multiple stakeholders to deliver locally focused community-led engagement with public health issues of national relevance. Through this collaborative effort and "ethic of mutual respect" (Earl, 2011), faith-based communities and governmental agencies have intentionally worked together for the common public good and wellness in addressing the communities' needs and to mitigate the impact of this global pandemic, COVID-19. To those of us who had worked with P4P, this was not a surprise. Pre-COVID Triedstone had led the way in pioneering pertinent research questions and selecting the appropriate methodologies to pilot a sustainable community-academic partnership between TRCDO and Northwestern University as authors now describe

\section{Research question/inquiry}

In PCORI-funded research, the focus of inquiry is science which leverages lived experience and expertise to influence research to be more patient-centered, relevant, and useful. The premise is that early and continued involvement throughout the phases of a research study can lead to greater use and uptake of research results by patients and stakeholders within the healthcare community. Key questions prefacing P4Ps building of a Community Support HUB have included asking faith-based leaders: (1) Why engage with research; and (2) When, how and where can my lived experience make a difference? Equally important for P4P has been the effort to document the journey and show that a grassroots-initiated $\mathrm{CAB} / \mathrm{HUB}$ model can deliver the key governance processes essential to the delivery of an effective research engagement infrastructure.

\section{Methodological Approaches}

In 2015, P4P was awarded its first Eugene Washington Award (EW) and became the first grassroots faith-based entity funded by PCORI to host and operationalize a network of churches interested in learning more about and patient centered research engagement. Between 2016 and 2018 , leaders of seventeen churches across Chicago ranging in size from less than 50 to over 2,000 members signed up to join the P4P network, completed Institute Review Board (IRB) training, and endorsed their representatives to be trained as P4P Research Ministry Ambassadors (RMAs) (see Appendix B). Figure 2 shows the geographical distribution of churches who completed Memorandum of Understanding (MOU), and sent church representatives to be trained as Research Ministry Ambassadors (RMA) and research survey methodology. Training was led by co-authors (RJ and DI), two academic partners from Northwestern and Rush Universities.

In 2017, building on the experiences of delivering the RMA program, Pastors4PCOR applied for and received a second EW engagement award for a Train-the-Trainer program (PCORI, 2017). Our goal was to equip others with the training tools and methods for engaging faith-based communities. 
Figure 2. Geographic distribution of participating churches.

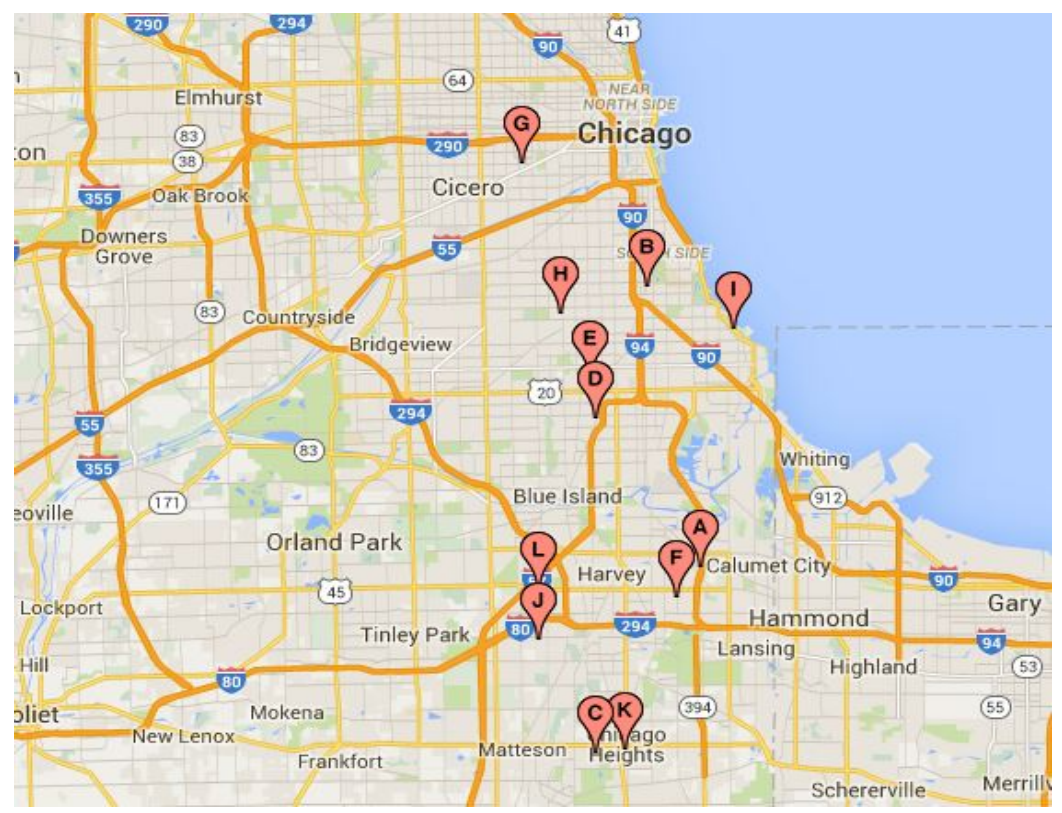

In 2019 P4P was awarded further funding to build community capacity to connect patients, stakeholders, and researchers.

Figure 3 illustrates the operative journey to date from CAB to Community Support HUB (PCORI, 2019). It should be noted that EW funding for capacity building was never guaranteed. The team submitted new applications for each contract. Success depended on the report of evidence of research engagement and success in P4Ps chosen methods.

Figure 3. from CAB to Community Support HUB (PCORI, 2019).

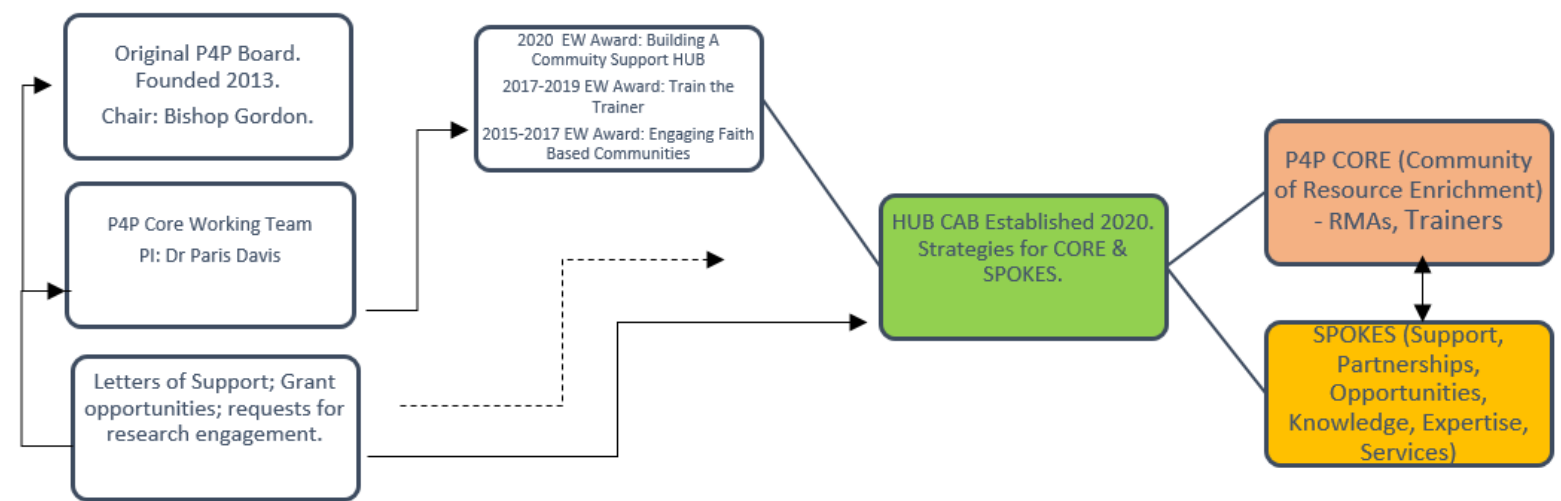

(C) The Author 2020. Published by the Coalition of Urban and Metropolitan Universities. www.cumuonline.org Metropolitan Universities | DOI 10.18060/24054 | December 18, 2020 
In what follows we share what we consider to be the essential components of our research engagement science.

Establishing a Community Advisory Board for the "beloved community" (Warren, et al., 2011). (1 ${ }^{\text {st }}$ EW Award: 2015-2017)

P4P's original Community Advisory Board (Table 1) was recruited from existing networks. An explicit goal of Patient-Centered Outcomes Research Institute (PCORI), authorized by United States Congress under the 2010 Affordable Care Act, is to increase minority ethnic representation in health research. Our CAB diversity was 70\% African American and 30\% White. PCORI holds accountable medical and public health researchers by ensuring that identifiable patient-focused proposals are submitted when seeking grant funds (PCORI, 2020). They also look for active engagement with the research cycle. CAB oversight was therefore guided by PCORI's principles and values. This means patient engagement is placed at the heart of practice and delivery of health disparities and health equity research (Huang, et al., 2017; TaiSeale, 2016).

The collaboratively authored vision for P4P (by its founders) was "to increase the participation of underserved communities of color in comparative effectiveness research and patient-centered outcomes research." CAB activity was informed by P4P's mission and vision "to inform, inspire and engage congregations in research through partnership" together with the longer term dream "to increase the participation of underserved communities in comparative effectiveness research and patient-centered outcomes research through the design, development, implementation, reporting, and dissemination of research."

Table 1. Pastor4PCOR Community Advisory Board: Original Member Role, Affiliation and Skills (2015)

\begin{tabular}{ccc}
\hline Board Role & Affiliation & Skills \\
Advisory Board Chair & Church Leader & Senior Pastor \\
Advisory Board Co- & Senior Church Leader & Reverend and Pastor \\
Chair & Church Elder, Lead Administrator & PhD, MBA \\
Executive Director & Academic Research Partner & PhD, researcher \\
Advisory Board & & \\
Member & Academic Research Partner & PhD, MPH, researcher \\
Advisory Board & &
\end{tabular}

(C) The Author 2020. Published by the Coalition of Urban and Metropolitan Universities. www.cumuonline.org Metropolitan Universities | DOI 10.18060/24054 | December 18, 2020 


$\begin{array}{lcc}\begin{array}{c}\text { Advisory Board } \\ \text { Member } \\ \text { Advisory Board } \\ \text { Member }\end{array} & \text { Community Advocate/Church member } & \text { MPH, LLC } \\ \begin{array}{c}\text { Advisory Board } \\ \text { Member }\end{array} & \text { Community Business Advocate } & \text { BA, JD, Policy Advocacy } \\ \begin{array}{c}\text { Advisory Board } \\ \text { Member }\end{array} & \text { Community Advocate/Church member } & \text { Patient/Caregiver } \\ \begin{array}{c}\text { Advisory Board } \\ \text { Member }\end{array} & \text { Church member } & \text { Advocacy } \\ \text { Advisory Board } & \text { Broadcast Journalism/Community } & \text { Patient } \\ \text { Member } & \text { Media } & \text { BS, MS }\end{array}$

The CAB's first major task was to guide the design and development of a Research Ministry Ambassador (RMA) training curriculum and materials suitable for faith-based community leaders and/or their nominated representatives and approve the engagement methods and strategies used to recruit participants.

The P4P CAB Chairperson enlisted the Executive Director (ED) of the home church's community development services (TRCDO) to oversee the management of a faith-based network infrastructure capable of recruitment. The ED created participant recruitment materials including information sheet, memoranda of understanding, data sharing agreement, pre and post-learner assessments, evaluations, and dissemination strategies. To join the network, a Pastor committed to sign a Memorandum of Understanding, nominated a church representative(s) to attend the training program and complete Institutional Review Board (IRB) certification.

\section{Developing a Research Engagement Training Program (2015-2017 and 2017-2019)}

Historical mistrust resulting from evident racism, discrimination, and bias is a key reason why underrepresented people and communities of color have negative perceptions of research, medical institutions, and researchers (Solomon, 2013). The Tuskegee clinical trials, the case of Henrietta Lacks and genetics research casts a long shadow within communities of color (Braithwaite, et al., 2020; Buseh, et al., 2013; Lee et al., 2019; Thompson, 2014). Community leaders also share frustration with researchers not sharing findings back to the communities participating (Petkovic et al., 2020).

(C) The Author 2020. Published by the Coalition of Urban and Metropolitan Universities. www.cumuonline.org Metropolitan Universities | DOI 10.18060/24054 | December 18, 2020 
As illustrated in Figure 4, P4Ps RMA training included preparing trainees to engage with research milestones. Five training modules orientated learners to the research cycle and included preparation to take a community health survey into the community.

Figure 4. Research Engagement Steps 1-5

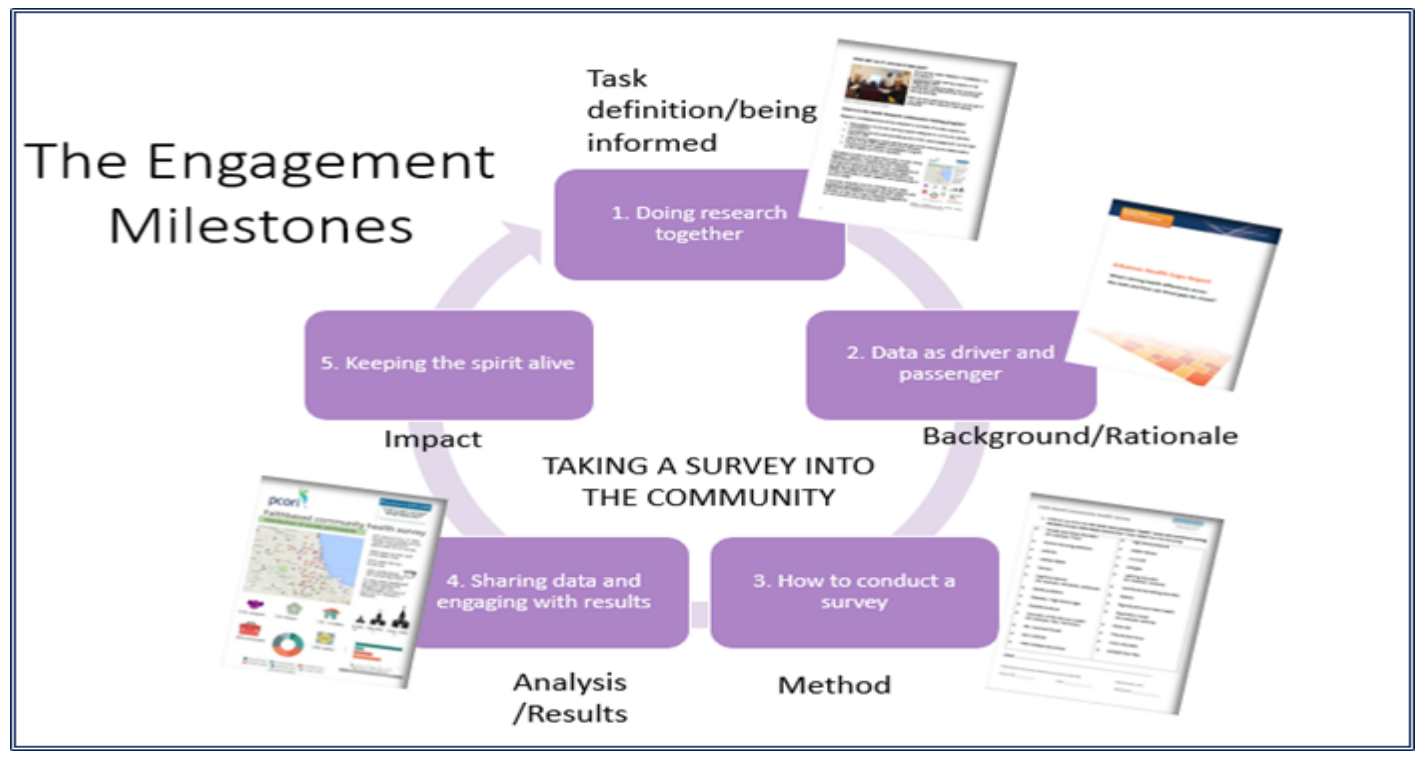

Although the education and training proposed was deemed to be IRB exempt, CAB board members were insistent that respectful research engagement behavior needed to be included in the RMA engagement training. IRB certification was made a program pre-requisite for both CAB membership and the trainees, Research Ministry Ambassadors (RMAs). The CAB agreed that it should be a pre-requisite for at least one representative from each church wishing to complete the survey component of the training program to have completed IRB training. IRB Reliance and Education Leads from the IRB Office of Northwestern University delivered interactive in-person human research protections certification training on three occasions for community partners and Certificates of completion. This CIRT-ification (Community Involvement in Research: Training for Community Partners) program includes: (1) Human Research Rules and Regulations; (2) Asking People to Participate in Research; (3) Being Careful with Research Information; and (4) How this all applies to you and your study. Developed specifically to meet the needs of community research partners, CIRT-ification was designed collaboratively by institutional review board and community-engaged research partners at University of Illinois at Chicago, University of Chicago, and Northwestern University. The popularity of the course with participants encouraged the P4P ED, Davis (co-author), to serve as an expert reviewer for an online training program in human research protections for community

(C) The Author 2020. Published by the Coalition of Urban and Metropolitan Universities. www.cumuonline.org Metropolitan Universities | DOI 10.18060/24054 | December 18, 2020 
research partners. Developed by a team at Loyola University, CIRTification online was launched in January 2020 (Matthews, et al., 2018).

Table 2. Community-based IRB Training (2015-2018)

Pastors, leaders and other church member participation in Community IRB Training

\begin{tabular}{|c|c|c|c|c|}
\hline Participants & $2015^{a}$ & $2016^{b}$ & $2018^{\mathrm{c}}$ & Comments \\
\hline $\begin{array}{l}\text { Pastors, Church } \\
\text { Leaders, and Advisory } \\
\text { Board members }\end{array}$ & 17 & - & - & \multirow{2}{*}{$\begin{array}{l}\text { "I liked the review of the Belmont } \\
\text { Report and the importance of informed } \\
\text { consent" (2016) } \\
\text { "I appreciate the pace and content } \\
\text { delivered during the training today" } \\
(2018) \\
\text { "Very informative information about } \\
\text { IRB" }\end{array}$} \\
\hline $\begin{array}{l}\text { Research Ministry } \\
\text { Trainees and Train-the- } \\
\text { Trainers** }\end{array}$ & 22 & 11 & 24 & \\
\hline Total & 39 & 11 & 24 & $\begin{array}{l}(100 \%) \text { agreed the understand the rules } \\
\text { and regulations protecting community } \\
\text { members. (2016). } \\
(67 \%) \text { agreed their knowledge/skills } \\
\text { regarding the ethical issues of doing } \\
\text { research together had significantly } \\
\text { increased. (42\%) agreed their knowledge } \\
\text { had somewhat Increased. (2018) }\end{array}$ \\
\hline
\end{tabular}

${ }^{a}$ IRB Training taster (2015)

${ }^{\mathrm{b}}$ IRB Training for period May - October (2016)

${ }^{\mathrm{C}}$ IRB Training for period January - September (2018)

\section{Analyses, Results and Legacy}

In Chicago, we know that each community has a unique sound. Our trained IRB-certified ambassadors have become bilingual in the languages of their communities and the language of the research world. Ongoing iterative evaluation of each phase of P4P's research engagement shows the impact our approach to engagement science has had on three key audiences. Firstly, on the community individuals who completed training and engaged community members in a basic survey of health conditions and health factors impacting faith-based communities.

Secondly, on the researchers who have engaged with P4P and thirdly, on stakeholders and policy makers who have supported the P4P mission since its inauguration. 
Impact on Faith-based Trainees and Communities

Improved education and understanding of patient-centered research engagement has been the biggest outcome for our faith-based community participants. A primary P4P CAB goal was to train a cadre of RMAs ready to serve as knowledgeable advocates for faith-based communities across Chicagoland (see Figure 2). Our hypothesis was that building the "research-ready" capacity of faith-based communities would not only promote equitable engagement with researchers within the medical and scientific arenas but also prepares these entities for nontraditional research engagement. The authors who are $\mathrm{P} 4 \mathrm{P}$ academic partners and co-founders jointly worked in developing the research educational program to provide the tools necessary for RMAs to understand and navigate databases and interpret health-related projects from design through implementation and dissemination of results. There was a crucial need to have the voice of the communities at the table when research topics are being developed and data collected and analyzed.

Learner pre and post-assessment of trainees was conducted by the academic trainers from Northwestern and Rush Universities (co-authors RJ and DI), to ensure continuous quality improvement and evaluation of the fit between training content and leaner expectations and experiences. The CAB-approved strategy facilitated accessible and easy monitoring of learner progress towards project aims and objectives and overall program performance. Using a single pre and post-assessment model supplemented by regular learner evaluation, the CAB used the data to iteratively review project progress and address issues as they arose. Data collected from pre and post-assessment included valuable demographic information about participant characteristics (see Appendix B). For example, participating Research Ministry Ambassadors, all of whom were members of faith-based communities across Chicagoland (Figure 2) shared that in their own church environments they held variety of church leadership roles: elders, pastors, and leaders of a church ministry (for example, members serving under ministries focusing on health, youths, caregivers, etc.). Trainers learned that RMAs represented churches of different sizes and that churches were varied in their use and familiarity with social media. Of note to researchers should be the need to take extra care when conducting pre-assessments. Pre-assessment took place during the first meeting of RMAs before IRB training. Everyone attending the session was new to the project and uncertain about its value and as a result unsure as to whether to trust the academic trainers and share information with them.

Upon completion of the training program, participants were asked to select all roles they would like to pursue post-training from the following list: (1) disseminate research findings; (2) join a PPRN; (3) renew community IRB; (4) conduct a second survey; (5) learn about clinical research; (6) become an educator about health behavior; (7) champion a health condition; (8) promote awareness about priority conditions; (9) become a trainer for research ministry; and (10) become a PCOR ambassador. They were also invited to pledge a project-related action for the coming year. Table 3 showcases a sample of pledges shared.

(C) The Author 2020. Published by the Coalition of Urban and Metropolitan Universities. www.cumuonline.org Metropolitan Universities | DOI 10.18060/24054 | December 18, 2020 
Table 3. Post Assessment Sample of RMA Pledges and Preferences

\begin{tabular}{|c|c|c|}
\hline Participants & Sample Pledges & $\begin{array}{l}\text { Engagement } \\
\text { Preferences }\end{array}$ \\
\hline $\begin{array}{l}\text { Research } \\
\text { Ministry } \\
\text { Trainees }\end{array}$ & $\begin{array}{l}\text { I have been energized to take things forward in } \\
\text { my faith-based community Health Ministry } \\
\text { I have truly been enlightened about how research } \\
\text { is so important } \\
\text { I pledge to help raise men's awareness about the } \\
\text { importance of participating in health research } \\
\text { I liked that I can help my congregation because I } \\
\text { am educated with information to help them have } \\
\text { a better quality of life. }\end{array}$ & $\begin{array}{l}\text { Become an educator } \\
\text { about health behavior } \\
\text { Conduct a second } \\
\text { survey } \\
\text { Learn about clinical } \\
\text { research } \\
\text { Promote awareness } \\
\text { about priority } \\
\text { conditions }\end{array}$ \\
\hline
\end{tabular}

Since its inception, P4P has graduated 72 IRB-certified Research Ministry Ambassadors (RMAs), trained 26 Research Ministry as Facilitators/Trainers (RMTs) from more than 12 zip codes and self-published the trainer facilitator manual, Engaging Faith-Based Communities with Health Research: Research Ministry Ambassador Facilitator Manual using Kindle Direct Publishing (Davis et al., 2017). During post-training sessions, trainers learned about some of the "ripple effect" (Hardy, et al., 2018) the community-based training program and research engagement had had on individual participants.

In actuality, several RMAs used their training and expertise to continue to engage with research. One RMA became a champion for a community engagement and early recognition project addressing disparities in stroke (the CEERIAS project). Another shared her expertise and knowledge of being an informal caregiver to improve home care aide understanding of client health and wellbeing topics for research (Johnson, et al., 2018) and was a key community stakeholder reviewer of a freely available website designed to assist seniors with later life planning (PCORI, 2017). Other RMAs are respected community voices within the UIC Cancer Center Patient Brigade (a group set up to ensure that the patients and communities have an active voice at the table regarding the center's research and community engagement activities), and the Chicago Community, Media and Research Partnership (PCORI, 2019) where the focus is to improve the dissemination and accessible communication of research findings. Two lay members of the CAB have served on PCORI National Advisory Panel on Patient Engagement. 12 RMAs continue to be members of the Pastors4PCOR Google classroom and GroupMe text. Members exchange resources and events, as well as, survey requests from trusted sources such as Illinois Department of Health (IDPH) and Chicago Department of Public Health (CDPH) and reflections

(C) The Author 2020. Published by the Coalition of Urban and Metropolitan Universities. www.cumuonline.org Metropolitan Universities | DOI 10.18060/24054 | December 18, 2020 
from events attended. RMAs have advocated for community members at research focused events on "Men Living Well with Sickle Cell" hosted at the University of Illinois at Chicago (UIC), Stem Cell Therapy and Regenerative Medicine hosted by the Bayer Stem Cell Institute and have co-presented at more community focused events such as the "Fourth Annual Faith, Health and Research Dialogue" hosted at Chicago State University (CSU). Learning, resources, and information from those events have been shared with other trained RMAs and also on church websites. In 2017, P4P successfully partnered with another PCORI EW awardee to build the capacity of a rural FAITH network to engage in research. Nine faith-based communities in and around the Little Rock, AR area undertook an abridged version of the training including taking the survey into the community.

\section{Impact on Researchers}

Community generated survey data has been the biggest factor in building our capacity to impact and partner with researchers. P4P developed and delivered two cycles of P4P Community Health Surveys that resulted in data collected from over 1,400 survey participants in Illinois and Arkansas. Dissemination of survey results via scientific poster presentation has proved particularly effective in communicating the aims and goals of the P4P partnership to public health researchers and clarifying our status as a community-based anchor. Since 2015, we have presented the results of our work by participating in both oral and poster presentations and/or as panel speakers at a range of academic, public health and community health conferences sponsored by important scientific and peer associations (e.g. PCORI, American Public Health Association, Society for Behavioral Medicine, Community-Campus Partnership for Health, Balm in GiLead Healthy Churches 2020), and local community health events. Going forward, HUB plans include co-authoring articles on the research educational program and community health survey results. Our CAB-approved dissemination policy requires community-academic coauthoring and co-presentation of all findings.

Our capacity to operate as an effective community-based anchor helped us to become a "test partner" in a PCORI funded comparative effectiveness study of treatments for one of the priority conditions flagged by community survey (heart disease). In collaboration with program lead, Duke Clinical Research Institute (DCRI, Duke University) and study site at Northwestern University (Evanston, Illinois), the P4P Network partnered with researchers on with ADAPTABLE (aspirin) study as one of two community-based organizations.

DCRI collected information on people with heart disease and the effects of taking a certain aspirin regimen [regular $(325 \mathrm{mg})$ or low-dose $(81 \mathrm{mg})$ aspirin] with goal to determine which dose of aspirin was better. Our network was utilized to assist in the recruitment of eligible participants. As a community partner under direction and subcontract of Northwestern University, P4P was responsible for assistance with the initial participant entry (recruitment) into 
the RedCap portal system for participant consenting, randomization and early visit conducted via the online patient portal format. The main goal of the trial partnership was to assess P4P's capacity to engage with clinical health researchers.

Valuable lessons learned from this "test partnership" between community anchor and clinical research team are fully documented elsewhere. (Zimmerman et al., 2018) Particular concerns and barriers to participation arose around differences in operational infrastructure, particularly budget and contractual issues, equipment and secured IT routes (off-campus); and registering P4P as a federally approved site for data collection. For example, academic institutions leading public health research characteristically operate cost-reimbursable subcontracts. This means communities invoice monthly to report work completed, whereas, community organizations would prefer to have a fixed cost deliverable contracts such as those offered by PCORI.

Building on this wealth of experience, the Pastors4PCOR network is continuing to work with the ADAPTABLE clinical research investigator. The ADAPTABLE Northwestern University lead researcher/partner supported P4P's engagement throughout the lengthy onboarding process. This persistence led to P4P serving as the community engagement partner lead (one of three PIs), on a recently awarded federally funded clinical trial with a goal to coordinate a community-centered intervention to reduce cardiovascular disease in Chicago (see Figure 1).

\section{Impact on Stakeholders and Policy Makers}

The multifaceted collaborative relationships formed during P4P's evolution from CAB to HUB (see Figure 3) has a lasting legacy. As detailed in the introduction to this article, from 2018 onward, we have engaged representatives from the Chicago 3 (C3) Clinical Translational Sciences Institutes (CTSIs) and the Chicago Department of Public Health (CDPH) in the building of the new HUB capacity to connect leaders of organizations to the lived experience of underserved members of communities across the Chicago area and vice versa. The HUB CAB includes members with affiliations and skills to advance research engagement driven by the community to impact data driven policy making. A Community of Research Enrichment (CORE) (which includes trained RMAs) is supported to take the lead in pinpointing topics and discussions for collaborative action. Stakeholders willing to provide access and linkage to knowledge, expertise, and services needed to progress research engagement identified by the community, are sources of Support, Partnership, Opportunities, Knowledge, Expertise and Services (SPOKES) (Figure 1). The HUB model allows for and facilitates the engagement of patients and stakeholders throughout the healthcare and research communities.

P4P's HUB CAB and CORE is also helping us to adapt and respond to COVID-19. Going forward, P4P aims to be a $21^{\text {st }}$ century community support HUB for research engagement relevant to post COVID-19 urban growth and quality of life. Through community-led research 
engagement, our HUB anticipates focusing on issues which align the incentives of faith-based communities, the private sector and federal, state, and local governments to unlock the full potential of the community. We anticipate that this will include housing, food, education, and access to healthcare in a world where insurance has disappeared along with job loss and COVID19 testing and social distancing have become the norm.

\section{Rationale and Reflection}

Racial and ethnic disparities in health and health care have long persisted in United States communities and one way to address this is to increase participation of underserved populations in health research. Pastors4PCOR (P4P) began this process by developing a CAB and training program to build capacity of faith-based communities to engage in equitable partnerships with researchers. Our Research Ministry Ambassadors (RMAs) have the tools to navigate and interpret research projects and conduct community asset mapping to describe key health priorities and resources within their community. In addition, the RMAs are equipped to interact with existing church ministries in caregiving, health care, and cluster engagement discussion groups on specific health topics.

This article provides additional evidence that faith-based communities can be valuable community-based anchors able to nurture and develop non-traditional research engagement in reducing health disparities and promoting health equity in practice and delivery. (Zimmerman et al., 2018; Richmond et al., 2017). Our approach illustrates how community-academic collaboration around health conditions and factors prioritized by faith-based communities can benefit communities. In addition, how community anchors can provide strategic oversight of multiple interventions as opposed to the more opportunistic engagement offered by university leads. The urgent need for continued accountability and attention to patient-focused experience has been evident during the current COVID-19 climate. In David Satcher's article, "The Impact of Disparities in Health on Pandemic Preparedness," he labels the greatest barriers to being prepared for a pandemic as health disparities and global heath inequities. These barriers impede pandemic preparedness due to disparities in health outcomes, health knowledge and awareness, early detection, early interventions as treatment and access to healthcare and treatments to prevent disease outcomes. A key component of attempts to overcome these barriers is being prepared and connected (Satcher, 2011).

\section{Conclusion}

As Bishop Simon Gordon, TFGBC Pastor and Chairperson of Pastor4PCOR, has observed while living in the face of the current global health pandemic, we see that our "community leadership and landscape are changing." Endemic longstanding issues of disparities in health care and economic hardships are not new challenges but rather stark realities and more commonly 
experienced by minorities and communities of color. By building the capacity of faith-based communities to lead research engagement with academic and medical researchers and health providers, $\mathrm{P} 4 \mathrm{P}$ aims to enable individuals and organizations new to research to identify health research questions which matter to them, and give them the information for how to make informed choices about participation in research studies. Learning about the process of engaging community members with collection of community health data about priority health conditions and factors impacting communities collected by our RMAs, shared and disaggregated by the P4P network has led to lively discussions within the community not only about participant experience of disseminating a survey but why survey respondents may have prioritized the conditions and factors as they did. P4P survey results underlined the need for better preventive education amongst faith-based communities around the prevalent health conditions impacting communities and better access to health care and supportive services. Since then, COVID-19 has provided real-time lived experience of how data and science can be used to inform policy makers, as well as, to show the strengths and weaknesses of data as a driver. The appropriate representatives now more than ever must be seated at the discussion table for important data interpretations, preparedness, community-based decisions to answer the call for action to mitigate adverse community impact during such critical times as an emergency, like a global public health pandemic.

\section{Acknowledgements}

We thank all CAB members, faith-based community leaders, and congregations who are part of the P4P network. This project was funded through a Patient-Centered Outcomes Research Institute (PCORI) Eugene Washington Award. The views presented in this article are solely the responsibility of the authors and do not necessarily represent the views of the PCORI, its Board of Governors, or Methodology Committee. 


\section{References}

Maurasse, D. (2001). Beyond the Campus: How colleges and universities form partnerships with their communities. New York: Routledge.

Council for Council for Advancement and Support in Higher Education. CASE, 2020. [Internet]. Available from: https://www.case.org/awards

Bamk, L., \& Nico, C. Eds. (2018). Anchored in Place: Rethinking the university and development in South Africa. Cape Town: African Minds.

Stoecker, R., \& Cutforth, N. (2003) Community-Based Research and Higher Education: Principles and Practices. Wiley.

Area Patient-Centered Outcomes Research Network (CAPriCORN, 2015). [Internet]. Available from: https://www.capricorncdrn.org/

Fritz, W., \& Iwama, K. (2019). The Power of Place-Based Legacies in Advancing Reengagement with Community. Metropolitan Universities, 30(2), 63-71. DOI: $10.18060 / 23368$

Harkavy I. (2016). Engaging Urban Universities as Anchor Institutions for Health Equity. American Journal of Public Health 106, 2155_2157. https://doi.org/10.2105/AJPH.2016.303475

Brewer, L.C., Balls-Berry, J.E., Dean, P., Lackore, K., Jenkins, S., \& Hayes, S.N. (2017) Fostering African-American Improvement in Total Health (FAITH!): An Application of the American Heart Association's Life's Simple $7^{\mathrm{TM}}$ among Midwestern AfricanAmericans. J Racial Ethn Health Disparities. April; 4 (2): 269-281.

Hankerson, S.H., Watson, K.T., Lukachko, A., Fullilove, M.T., \& Weissman, M. (2013) Minister's Perceptions of church-Based Programs to Provide Depression Care for African Americans. Journal of Urban Health: Bulletin of the New York Academy of Medicine. 90 (4): 685-698.

Hou, S., \& Cao, X. (2017) A Systematic Review of Promising Strategies of Faith-Based Cancer Education and Lifestyle Interventions Among Racial/Ethnic Minority Groups. J Canc Educ. September 13; 1161-1175.

Misra, R., Fitch, C., Roberts, D., \& Wright, D. (2016) Community-Based Diabetes Screening and Risk Assessment in Rural West Virginia. Journal of Diabetes Research. 1-9. 
Plunkett, R., \& Chen, P. (2015). Supporting healthy dementia culture: An exploratory study of the church. Journal of Religion and Health. 55 (6): 1917-1928.

Campbell, M.K., Hudson, M.A., Resnicow, K., Blakeney, N., Paxton, A., \& Baskin, M. (2007) Church-Based Health Promotion Interventions: Evidence and Lessons Learned. Annual Review of Public Health. 28(1): 213-234.

Kennedy, B.R., Mathis, C.C., \& Woods, A.K. (2007). African Americans and Their distrust of Health Care System: Healthcare for Diverse Populations. Journal of Cultural Diversity. $14(2) ; 56-60$.

Park, S.E., Mosley, J.E., \& Grogan, C.M. (2016). Do Residents of Low-Income Communities Trust Organizations to Speak on their Behalf? Differences by Organizational Type. Urban Affairs Review.1-28.

Kiger, A.M., Fagan, D.M., \& van Teijlingen, E.R. (2017). Faith Communities and the Potential for Health Promotion. Health and Risk Communication. Online Publication Date: May.

Scriven, D. (2011). Hindsight, irony, and the ethical: a commentary on pandemics, social distancing, and community mitigation strategies involving African American clergy. $J$ Health Care Poor Underserved. Aug 22 (3 Suppl):38-42.

Jewett-Tennant, J., Collins, C., Matloub, J., Patrick, A., Chupp, M.,Werner, M.J., \& Borawski, E,A. (2016). Partnership Among Peers: Lessons Learned From the Development of a Community Organization-Academic Research Training Program. Prog Community Health Partnersh. 10(3): 461-470.

Adebayo, O.W., Salerno, J.P., Francillon, V., \& Williams, J.R. (2018) A systematic review of components of community-based organization engagement. 2018. Health Soc Care Community. Jul; 26(4): e474-e484. Published online 2018 Jan.

Yamamura, E., \& Koth, K. (2018) Place-Based Community Engagement in Higher Education: A Strategy to Transform Universities and Communities. Stylus: Sterling: Virginia.

Friedman, D., Perry, D., \& Menendez, C. (2014) The Foundational Role of Universities as Anchor Institutions in Urban Development. [Internet] https://usucoalition.org/images/APLU_USU_Foundational_FNLlo.pdf 
Brooks, R.G., \& Koenig, H.G. Editorial: Crossing the Secular Divide: Government and FaithBased Organizations as Partners in Health. Int'l J. Psychiatry in Medicine. 2002: 32 (3): 223-234.

DeHaven, M., Hunter, I., Wilder, L., Watson, J., \& Berry, J. (2004). Health Programs in Faith Based Organizations: Are they Effective? American Journal of Public Health. 94 (6): 1030-1036.

Kang, M. (2016). Moderating effects of identification on volunteer engagement: An exploratory study of a faith-based charity organization. Journal of Communication Management (JCO). 2016; 20 (2): 102-117.

Khubchandani J., Balls-Berry, J., Price, J.H., \& Webb, F.J. (2016). Community-Engaged Strategies to Increase Diversity of Participants in Health Education Research. Health Promotion Practice. May; 17 (3): 323-327.

Olivier, J. (2017) Guest editor conclusion: research agenda-setting for faith and health in development - where to now? Development in Practice. 27 (5): 775-781.

Tucker, C.M., Wippold, G.M., Williams, J.L., Arthur, T.M., Desmond, F.F., \& Robinson, K.C. (2017). A CBPR Study to Test the Impact of a Church-Based Health Empowerment Program on Health Behaviors and Health Outcomes of Black Adult Churchgoers. $J$ Racial and Ethnic Disparities. 4:70-78.

Sanders, T. (2016). David and Goliath: dismantling inequalities within faith-based cross-sector partnership. Development in Practice. 26 (7): 892-905.

Warren, R.C., Walker, B. Jr., Maclin, S.D. Jr., et al. (2011). Respecting and protecting the beloved community, especially susceptible and vulnerable populations. Journal of Health Care for the Poor and Underserved. 2011 August 22 (3 Suppl):3-13.

CDC Coronavirus Disease 2020 (2020). [Internet]. Available from: https://www.cdc.gov/coronavirus/2019-ncov/need-extra-precautions/racial-ethnicminorities.html

Chicago Urban League (2020). An Epidemic of Inequities: Structural Racism and COVID-19 in the Black Community. Longstanding structural racism and inequity contribute to a range of risk factors that make Black Americans more likely to contract and die from COVID19. [Internet]. Available at: https://https://chiul.org/wpcontent/uploads/2020/05/ChicagoUrbanLeague_An-Epidemic-of-Inequities_5-12-20.pdf 
CDPH COVID - 19 Response Center [Internet]. Available at: https://www.chicago.gov/city/en/sites/covid-19/home.html

South-Side Weekly (2020) [Internet]. Available at: https://southsideweekly.com/live-candetermine-health-note-april-2020/

Triedstone Full Gospel Baptist Church. 2020. [Internet]. Available at http://triedstonecoc.com/ Chicago Health Atlas. (2020). [Internet]. Available at: https://www.chicagohealthatlas.org/

Chicagobusiness.com. 2020. [Internet]. Available at: https://www.chicagobusiness.com/greghinz-politics/pritzker-vows-step-covid-fight-african-american-community

Earl Jr., R. R. (2011). Emergency Preparedness for a Pandemic Influenza: Ethical Challenges for Black Ministers and the Public Health Community. Journal of Health Care for the Poor and Underserved. Vol 22, Number 3, August, Supplement, pp. 14-18.

TRCDO (2020). [Internet]. Available at: http://triedstonecoc.com/about-us/our-partners/totalresource-cdo/

Johnson, R., Davis, P., Ingram, D., Greer-Smith, R., \& Gordon, S. (2020) Community-Initiated Research Engagement: Equitable Partnership Delivering Research-Ready Faith-Based Ambassadors. Progress in Community Health Partnerships: Research, Education, and Action. Summer. Volume 14:2.

PCORI Engagement Rubric. Patient Centered Outcomes Research Institute website (PCORI). [Internet]. Available from: https://www.pcori.org/sites/default/files/EngagementRubric.pdf

P4P. Engaging Faith-based communities [Internet]. Available from: www.pcori.org/researchresults/2015/pastors-4-pcor-engaging -faith-based-communities

P4P.Facilitator Training [internet]. Available from: https://www.pcori.org/researchresults/2017/pastors4pcor-facilitator-training-research-ministry-ambassadors

P4P. Community HUB. [Internet]. Available from: https://www.pcori.org/researchresults/2019/building-community-support-hub-connecting-patients-stakeholders-and

(C) The Author 2020. Published by the Coalition of Urban and Metropolitan Universities. www.cumuonline.org Metropolitan Universities | DOI 10.18060/24054 | December 18, 2020 
Huang, J., Lipman, P.D., Mullins C.D. (2017). Bridging the divide: building infrastructure to support community-academic partnerships and improve capacity to conduct patientcentered outcomes research. The Society of Behavioral Medicine (TBM). 03 April; 1-10.

Tai-Seale M., Sullivan G., Cheney, A., Thomas, K., \& Frosch, D. (2016) The language of engagement: "Aha!" moments from engaging patients and community partners in two pilot projects of the Patient-Centered Outcomes Research Institute. Perm J. Spring; 20(2):89-92

Patient Centered Outcomes Research Institute website. PCORI home page. Available from: www.pcori.org

Solomon, S. R. (2013). Protecting and respecting the vulnerable: existing regulations or further protections?. Theoretical medicine and bioethics, 34(1), 17-28.

Buseh, A.G., Stevens, P.E., Millon-Underwood, S., Townsend, \& L., Kelber. (2013) Community leader's perspectives on engaging African Americans in biobanks and other human genetic initiatives. Journal of Community Genetics 4:483-494.

Lee, S.S.J., Cho, M.K., \& Kraft, S.A., et al. (2019). "I don't want to be Henrietta Lacks": Diverse Patient Perspectives n Donating Biospecimens for Precision Medicine Research. Genetic Medicine. 2019 January; 21 (1): 107-113.

Thompson, W., Pattillo, R. A., Stiles, J.K., \& Schatten, G. (2014). Biomedical research's unpaid debt: NIH's initiative to support and implement fairer competition for minority students is a welcome step to redress the exploitation of African Americans by science. $E M B$ reports, Science \& Society (2014) Volume 15, No 4.

Petkovic, J., Riddle, A., \& Aki, E.E. (2020). Protocol for the development of guidance for stakeholder engagement in health and healthcare guideline development and implementation. Systematic Reviews. 9:21

Cirtification. 2020. [Internet]. Available from: www.ccts.uic.edu/content/cirtification.

Arkansas Faith Academic Initiative for Transforming Health [Internet]. Available from: www.pcori.org/research-results/2017/development-arkansas-faith-academic-initiativestransforming-health-faith

Matthews, A.K., Anderson, E.E., Willis, M., Castillo, A., \& Choure, W. (2018). A Community Engagement Advisory Board as a Strategy to Improve Research Engagement and Build

(C) The Author 2020. Published by the Coalition of Urban and Metropolitan Universities. www.cumuonline.org Metropolitan Universities | DOI 10.18060/24054 | December 18, 2020 
Institutional Capacity for Community Engaged Research. Journal of Clinical and Translational Science. 2(2): 66-72.

P4P. Engaging Faith-Based Communities with Health Research: Research Ministry Ambassador Facilitator Manual using Kindle Direct Publishing [Internet]. Available from: https://www.amazon.com/Engaging-Faith-Communities-Health-Researchebook/dp/B07K83QBD5

Hardy, J., Hulen, E., Shaw, K., Mundell, L. (2018). Ripple effect: An evaluation tool for increasing connectedness through community health partnerships. Action Research. Vol. 16(3) 299-318.

CEERIAS [Internet]. Available from: https://www.pcori.org/research-results/2014/communityengagement-early-recognition-and-immediate-action-stroke-ceerias

ADAPTABLE [Internet]. Available from: http://theaspirinstudy.org/

CCMRP [Internet]. Available from: https://publicnarrative.org/2019/10/announcing-the-chicagocommunity-media-research-partnership/

Johnson, R., Diaz, L., Boyken, L., Saberbein, G., Rogers B., \& Smith, P., Rodriguez, L., \& Danilovich, M. (2019) Developing a health interview tool for Medicaid home and community-based services clients and home care aides through a community-engaged approach. Home Health Care Serv Q. Jan-Mar; 38(1):1-13

Zimmerman, L. P., Goel, S., Sathar, S., Gladfelter, S., et al. (2018). A Novel Patient Recruitment Strategy: Patient Selection Directly from the Community through Linkage to Clinical Data. Appl. Clin. Inform. Jan 9 (1) 114-121.

PCORI Patient Advisory Panel [Internet]. Available from: https://www.pcori.org/engagement/engage-us/pcoris-advisory-panels/advisory-panelpatient-engagement/biographies-advisory

Satcher, D. (2011). The Impact of Disparities in Health on Pandemic Preparedness. Journal of Health Care for the Poor and Underserved. Vol 22, Number 3, August, Supplement, pp. 36-37. 
Appendix A

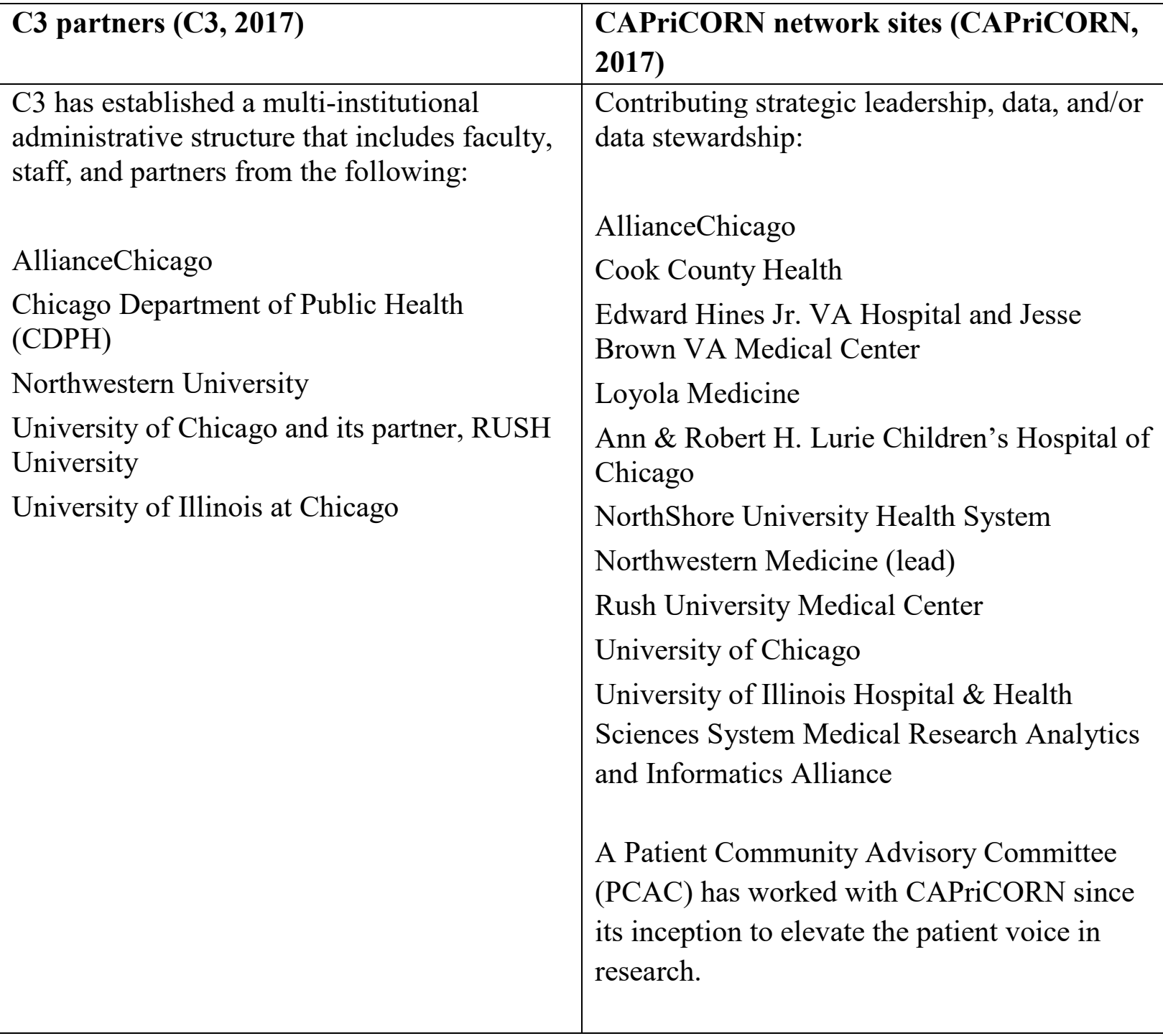

\section{Appendix B}

Demographics of Research Ministry Ambassadors (RMA) participating in training at Triedstone Full Gospel Baptist Church (pre-assessments conducted in 2016 and 2018)

\begin{tabular}{|l|l|l|}
\hline Demographics & $\mathbf{2 0 1 6}$ & $\mathbf{2 0 1 8}$ \\
\hline Participants in RMA training & $\mathbf{N}(\mathbf{\%})$ & $\mathbf{N}(\mathbf{\%})$ \\
\hline Total & $\mathbf{2 0}(\mathbf{1 0 0 \% )}$ & $\mathbf{1 6}(\mathbf{1 0 0 \% )}$ \\
\hline Age Category (years) & & \\
\hline $18-24$ & 0 & 2 \\
\hline $25-39$ & 4 & 3 \\
\hline $40-49$ & $6(30 \%)$ & $5(31 \%)$ \\
\hline
\end{tabular}

(C) The Author 2020. Published by the Coalition of Urban and Metropolitan Universities. www.cumuonline.org 


\begin{tabular}{|l|c|c|}
\hline $50-59$ & $6(30 \%)$ & 2 \\
\hline 60 and over & 4 & 3 \\
\hline DNA & 0 & 1 \\
\hline Gender & 4 & 5 \\
\hline Male & $16(80 \%)$ & $11(69 \%)$ \\
\hline Female & 0 & 0 \\
\hline Missing & & \\
\hline Race & $20(100 \%)$ & $16(100 \%)$ \\
\hline Black or African American & & \\
\hline Education & 0 & 0 \\
\hline Less than high school & 4 & 2 \\
\hline High school diploma (GED) & $15(75 \%)$ & $12(75 \%)$ \\
\hline College degree or higher & & 2 \\
\hline Some college & 1 & \\
\hline Missing & & \\
\hline Faith-based Community (congregation size) & 0 & 3 \\
\hline $26-100$ & $6(30 \%)$ & $5(31 \%)$ \\
\hline $101-499$ & 1 & 4 \\
\hline $500-999$ & 1 & 1 \\
\hline $1,000-1,499$ & 1 & 1 \\
\hline Over 2,000 & 4 & $\mathbf{0}$ \\
\hline Not Known & & \\
\hline Social Media used by participants & 18 & 13 \\
\hline Internet & 15 & 13 \\
\hline Smart phone & $20(100 \%)$ & 13 \\
\hline Email & 0 & 11 \\
\hline Facebook & 0 & 5 \\
\hline Twitter & 0 & 0 \\
\hline Don't use & 19 & 13 \\
\hline Social Media used by home church & 18 & 12 \\
\hline Internet & 7 & 7 \\
\hline Smart phone & 0 & 0 \\
\hline Email & & \\
\hline Twitter & & 11 \\
\hline Facebook & & \\
\hline Don't use & & \\
\hline
\end{tabular}

